Edith Cowan University

Research Online

Research outputs 2014 to 2021

5-1-2019

\title{
A 2-year prospective study of injury epidemiology in elite Australian rugby sevens: Exploration of incidence rates, severity, injury type, and subsequent injury in men and women
}

\author{
Liam A. Toohey \\ Michael K. Drew \\ Caroline F. Finch \\ Edith Cowan University \\ Jill L. Cook \\ Lauren V. Fortington \\ Edith Cowan University
}

Follow this and additional works at: https://ro.ecu.edu.au/ecuworkspost2013

Part of the Sports Sciences Commons

$10.1177 / 0363546518825380$

This is an Author's Accepted Manuscript of: Toohey, L. A., Drew, M. K., Finch, C. F., Cook, J. L., \& Fortington, L. V. (2019). A 2-year prospective study of injury epidemiology in elite Australian rugby sevens: Exploration of incidence rates, severity, injury type, and subsequent injury in men and women. The American Journal of Sports Medicine, 47(6), 1302-1311.

https://doi.org/10.1177/0363546518825380

This Journal Article is posted at Research Online.

https://ro.ecu.edu.au/ecuworkspost2013/6259 
1 A two-year prospective study of injury epidemiology in elite Australian rugby sevens: exploration of 2 incidence rates, severity, injury type and subsequent injury in men and women 
1

2

3

4

7 Study design: Descriptive longitudinal epidemiology study.

\section{ABSTRACT} continuous time periods, and reporting of match injuries only. occurrence in rugby sevens, looking beyond tournament-injuries only.

Background: Injuries are common in rugby sevens but studies to date have been limited to short, non-

Purpose: To report the injury incidence rate (IIR), severity and burden of injuries sustained by men and women in the Australian rugby sevens program; and to provide the first longitudinal investigation of subsequent injury

8

Methods: 90 international rugby sevens players (55 men and 35 women) were prospectively followed over two consecutive seasons (2015-16 and 2016-2017). All medical attention injuries were reported irrespective of timeloss. Individual exposure, in terms of minutes, distance and high speed distance, was captured for each player for matches and on-field training using global positioning system (GPS) devices. The IIR and injury burden (IIR $\mathrm{x}$ days lost to injury) were calculated per 1000 player hours, and descriptive analyses performed.

Results: 73 players (81.1\%) sustained 365 injuries at an IIR of 43.2 per 1000 player hours (95\%CI 38.8-47.8). Female players experienced a lower but non-significant IIR compared to male players (incidence rate ratio $(I R R)=0.91,95 \% \mathrm{CI}=0.73$ to 1.12 ). Female players sustained a higher proportion of injuries to the trunk region (relative risk $(\mathrm{RR})=1.75,95 \% \mathrm{CI}=1.28$ to 2.40$)$ but a lower number to the head/neck region $(\mathrm{RR}=0.58$, $95 \% \mathrm{CI}=0.37$ to $0.93, \mathrm{p}=0.011)$ compared to male players. The majority $(80.7 \%)$ of subsequent injuries were of a different site and different nature to previous injuries. A trend towards a reduced number of days, participation time, distance and high speed distance completed prior to the next injury was observed following successive injury occurrence.

Conclusions: A trend for a lower IIR was observed for female players compared to male players, with variation of injury profiles observed between sexes. Subsequent injuries account for the majority of injuries sustained in rugby sevens, and are typically different to previous types of injuries that have been sustained. Following each successive injury, the risk profile for future injury occurrence appears to be altered, which warrants further investigation to inform injury prevention strategies in rugby sevens.

Key terms: athletic injuries, sports medicine, prospective studies, epidemiology, sports 


\section{What is known about the subject?}

2 Rugby sevens has become an increasingly popular sport since its introduction into the 2016 Olympic Games.

3 Published injury profiles in rugby sevens are limited by including only tournament-sustained injuries. However,

4 these reports suggest injury risk to be substantially higher than many other sports. There is currently very

5 limited evidence that compares the injury profile from rugby sevens between men and women. No study has

6 examined the characteristics of subsequent injury in rugby sevens previously.

\section{What this study adds to existing knowledge:}

8 This study describes all injury and subsequent injury occurrence for rugby sevens over an extended continuous

9 surveillance period inclusive of both match and training related injuries for both men and women for the first

10 time. The injury profile for male and female players differed, suggesting the need for different priorities for

11 injury prevention strategies based on player sex. Workload and time exposure before injury substantially reduced after the occurrence of each successive injury, suggesting that players might become less tolerant to the physical demands of the sport and increasingly susceptible to subsequent injury following an accumulation of previous injuries. The findings in this paper provide a basis for future exploration into the aetiology and mechanisms of injury, particularly investigating tertiary prevention strategies for mitigating the risk of subsequent injury occurrence in rugby sevens. 
2 There is a growing interest in the sport of rugby sevens, following its introduction at the 2016 Olympic

3 Games. ${ }^{38}$ A variant of the traditional 15-a-side rugby union, rugby sevens is comprised of seven players per

4 team competing over two 7-minute halves on a regular size rugby field with similar rules as rugby union.

5 Matches are high-paced ${ }^{3}$ and, because there are fewer players per side and a shorter duration of play compared

6 to the traditional format, rugby sevens players require different tactics, skills and physical demands. ${ }^{33,34}$ Recent

7 publications have considered injury, competition, training and match demands of rugby sevens. ${ }^{3,24,25,29,30}$ Injury comparisons between rugby sevens and union, suggest rugby sevens has a higher rate of injuries that are also typically more severe, causing a longer duration of missed time than injuries in rugby union. ${ }^{3,21}$ The higher injury rates in rugby sevens have been hypothesised to occur due to faster game play and fewer players, leading to fatigue, coupled with multiple matches played back-to-back over a 2-day tournament-style competition. ${ }^{23} \mathrm{Not}$ to be discounted is the longer history of injury prevention research and injury prevention measures in rugby union compared to only a small number of descriptive studies in rugby sevens, which are largely limited to elite male cohorts. ${ }^{3,38}$

The World Series injury reports by World Rugby, ${ }^{11-16}$ and descriptive injury papers in rugby sevens, ${ }^{4,20,21,27}$ have improved understanding of match injuries, but have not considered injury data reporting across tournaments. ${ }^{3,37}$ Longer prospective surveillance in rugby sevens cohorts is required to investigate not only the match-focused outcomes, but also to consider injury patterns over successive tournaments as well as training and pre-season periods where a proportion of injuries are likely to occur..$^{7,10,37}$ Through monitoring and reporting all of the injuries sustained over time, a greater understanding of the most burdensome injuries that occur in rugby sevens squads can be ascertained. This information is needed to prioritise prevention areas and drive changes to improve player safety.

The majority of rugby sevens players will experience multiple injuries over time. ${ }^{37}$ The probability of an injury (either exactly the same injury or a different injury) is strongly influenced by previous injury occurrences, ${ }^{36}$ but the inter-relationship between injuries remains poorly understood. ${ }^{5,8,37}$ To date, multiple individual injuries in studies of team ball sports have largely been ignored within reporting and analyses or they have been addressed through a restricted definition of 'recurrence' only. ${ }^{10}$ Recurrent injuries include only those with the exact same nature and at the exact same site of an earlier sustained injury. ${ }^{19}$ Identification that recurrent injuries only account for a small proportion of subsequent injuries, ${ }^{1,5,6,31,37}$ justifies the objective to look more broadly at 
relationships between injuries of a different body part and nature to assist in the development of successful injury prevention strategies that account for these relationships. ${ }^{5,6,36,37}$

Gaining a detailed understanding of the injury characteristics in rugby sevens is essential to guide future injury prevention strategies specifically targeted to the needs of rugby sevens players. ${ }^{26}$ The Australian rugby sevens program includes both a men's and women's squad. Both squads utilise the same injury reporting and workload capture methodologies, providing a unique situation to accurately compare injury patterns from both the men's and women's teams. The aims of this study were firstly to report the frequency, severity, incidence and burden of injuries sustained by men and women in the Australian rugby sevens program and secondly, to provide the first detailed longitudinal investigation of subsequent injury occurrence in rugby sevens, looking beyond matchloss injuries only.

\section{METHODS}

\section{Study design and population}

All members of the men's and women's Australian international rugby sevens squads were prospectively followed over two consecutive seasons (Season 2015/16: September $1^{\text {st }} 2015$ to August $31^{\text {st }}$ 2016; Season 2016/17: September $1^{\text {st }} 2016$ to August $31^{\text {st }}$ 2017). All injuries that were sustained during the surveillance period, including during the pre-season, in-season and off-season periods, were recorded with no players excluded from the analysis. Players within the national squads train throughout the year and play intermittently in international competitions (World Rugby Sevens Series). The reporting of this study follows the Strengthening the Reporting of Observational studies in Epidemiology (STROBE) statement. ${ }^{39}$

Ethics approval was obtained from (C17-006). All participants provided written consent for the Australian Rugby Union (ARU) to share their injury and match data prior to participation. Data were provided to the research team in a format re-identifiable only to the ARU data management team, using a unique player ID code.

\section{Injury definitions}

An injury was defined as a medically diagnosed physical complaint that was sustained while undertaking rugby training or rugby competition that resulted in loss or abnormality of bodily structure or functioning, irrespective of time-loss from rugby activities. ${ }^{19}$ This is consistent with the medical-attention injury definition described in 
the rugby union consensus statement on recording and reporting injury. ${ }^{19}$ Injuries were sub-categorised as timeloss injuries when the injury caused the player to be unable to participate in rugby training or competition, for greater than 24 hours following the day of injury, irrespective of whether match or training sessions were actually scheduled. ${ }^{19}$ Injuries to specific body sites were categorised into body regions according to the rugby union injury reporting consensus guidelines. ${ }^{19}$ A subsequent injury was defined as any injury sustained following the initial injury sustained within the surveillance period ${ }^{5}$ and further sub-categorised retrospectively into one of the eight data-driven categories of the revised subsequent injury categorisation model (SIC-2.0) using the automated coding methods that have been published and described in detail elsewhere. ${ }^{37}$

\section{Injury data collection}

All injury data were prospectively collected and recorded in a centralised database (Smartabase, Fusion Sport Pty Ltd, Brisbane Australia) by the teams' qualified medical personnel (sports physiotherapist or sports physician). Each injury was assigned a four-character Orchard Sports Injury Classification System 10 (OSICS10.1) injury diagnosis code, which details the body part and nature of the injury sustained. ${ }^{32}$ In addition, information was recorded to identify the body side of the injury (i.e. left, right, bilateral, central), date of injury occurrence, date of return to training, date of full injury resolution, the number of days the player was unable to participate both fully and partially in rugby training and/or competition. Information about the specific injury mechanism and activity were not used in this study due to their inconsistent recording in the database. All data were linked by a unique ID and injuries were time ordered according to the date of injury for each injured player, in accordance with published data guidelines. ${ }^{7}$

\section{Collection and quantification of rugby sevens exposure}

Individual player exposure was prospectively captured throughout the surveillance period for all on-field training sessions and matches using a global positioning system (GPS) device (GPSports, SPI HPU, Canberra, Australia). These data were uploaded and stored in a centralised database (Smartabase, Fusion Sport, QLD, Australia). Data were provided to the research team in a de-identifiable format, using the same unique ID used for the injury data, allowing the two data sets to be linked.

Multiple external loads were measured using the GPS units. Duration was defined as the total time (minutes) elapsed during rugby training or competition related activity including warm-up and cool-down periods; distance was defined as the total distance covered (m), including walking, running and sprinting; and high speed running was defined as the total distance covered (m) for running speeds captured greater than $5 \mathrm{~m} / \mathrm{s}$. In the 
instances where a player completed multiple training sessions or multiple games on the one date, sessional data was collapsed to obtain a daily total of the distance covered and duration completed for these dates.

\section{Analyses}

Descriptive analyses were performed separately for men and women to enable comparison to previous literature. Descriptive data are presented both separately and combined for injuries sustained in each year of surveillance, corresponding to the 2015-16 and 2016-17 Sevens World Series seasons. The magnitude of difference between the proportions of specified injury variables in men and women were measured by relative risks (RR), with men as the reference category $(\mathrm{RR}=1.00)$, and their associated 95\%CIs, with Fisher's exact test used to test for significance set a priori at $\mathrm{p}$-value $<0.05 .^{28}$

Injury incidence rates for men and women, for each season, were calculated using the following formula: number of injuries/exposure in hours (individual hours collected from GPS) x1000. Poisson 95\%CIs for incidence rates were calculated, and incidence rates were assessed using incidence rate ratios (IRRs) and their associated 95\%CIs. Statistically significant differences were determined when the 95\%CIs did not include IRR=1.0. Injury burden was calculated using the following formula: mean severity (number of days lost before full return to training/match) $\mathrm{x}$ injury incidence. The ten injuries with the largest burden for each sex were plotted graphically in an injury risk (burden) matrix, where the mean injury severity (time-loss days) was plotted against the injury incidence. ${ }^{17,18}$ All statistical analyses was performed in Stata (Stata/IC 15.1, StataCorp, USA).

\section{RESULTS}

\section{Participation and injury occurrence}

A total of 90 players (55 men and 35 women) were under surveillance during the 2 -year period over which a total of 8457 on-field player participation hours were completed. Of these players, 42 (20 men and 22 women) participated in both the 2015-16 and 2016-17 seasons. A total of 365 injuries were reported over the 2-year surveillance period, sustained by 73 players $(81.1 \%)$ at an incidence rate of 43.2 (38.8 to 47.8$)$ per 1000 player hours. A $36 \%$ increase in the rate of injuries was observed in the 2016-17 season compared to the 2015-16 season $(\mathrm{IRR}=1.36,95 \% \mathrm{CI}=1.10$ to 1.70$)$, which was similarly found in the men's squad (IRR=1.39, $95 \% \mathrm{CI}=1.05$ to 1.85$)$, however this was not significant in the women's squad (IRR=1.32, 95\% CI=1.94 to 1.87$)$. The majority of reported injuries (79.2\%) resulted in time-loss from training or competition (Table 1). 


\section{Type of injuries sustained}

The majority of injuries sustained were to the lower-limb (58.3\%) or upper-limb (21.4\%), which resulted in a median time-loss periods of 14 days (interquartile range $(\mathrm{IQR})=43)$ and 15 days $(\mathrm{IQR}=45)$, respectively. More specifically, the knee (13.2\%), head (12.6\%), and thigh (12.6\%) were the most common body sites injured, with median time-loss periods of 30 days (IQR=91), 8 days ( $\mathrm{IQR}=16$ ), and 15 days (IQR=30). More than a quarter $(25.2 \%)$ of all injuries were joint sprains and $16.7 \%$ of injuries were of a muscular nature, where median timeloss periods of 23 days (IQR=49) and $11(\mathrm{IQR}=22)$ occurred, respectively (Table 2).

\section{Comparison of injury in men and women}

From the men's squad, forty-six (83.6\%) players (age=24.0 \pm 3.8$)$ sustained a total of 213 injuries $($ median=3, $\mathrm{IQR}=6$, range 1-12), while from the women's squad $27(77.1 \%)$ players (age=22.9 \pm 3.1$)$ sustained 152 injuries (median=4, IQR=6, range=1-15) over the 2-year surveillance period. Players from the women's squad (IIR=40.8, 95\% CI=34.5, 47.8, per 1000 player hours) were found to have a lower but non-significant IIR compared to the men's squad (IIR=45.0, 95\% CI=39.2, 51.5, per 1000 player hours $)(I R R=0.91,95 \% C I=0.73$ to 1.12). This finding was also observed for the $2015-16$ season (IRR=0.93, $95 \% \mathrm{CI}=0.63$ to 1.31 ), the $2016-17$ season $(\mathrm{IRR}=0.88,95 \% \mathrm{CI}=0.67$ to 1.16$)$, and for those players who participated in both seasons (IRR=0.99, $95 \% \mathrm{CI}=0.77$ to 1.27 ). Compared with the men's squad, the women's squad had a lower but non-significant rate of both time-loss injuries $(\mathrm{IRR}=0.90,95 \% \mathrm{CI}=0.71$ to 1.14$)$, and non-time loss injuries (IRR=0.92, $95 \% \mathrm{CI}=0.57$ to 1.49$)$.

When compared to the men's squad, women were more likely to sustain an injury to the trunk region $(\mathrm{RR}=1.75$, $95 \% \mathrm{CI}=1.28$ to $2.40, \mathrm{p}=0.010)$, but were less likely to sustain an injury to the head/neck region $(\mathrm{RR}=0.58$, $95 \% \mathrm{CI}=0.37$ to $0.93, \mathrm{p}=0.011$ ). More specifically, women had an increased RR of sustaining a hip/groin injury $(\mathrm{RR}=1.67,95 \% \mathrm{CI}=1.22$ to $2.28, \mathrm{p}=0.017)$, and an increased risk in sustaining a lumbar spine injury $(\mathrm{RR}=1.91$, $95 \% \mathrm{CI}=1.38$ to $2.64, \mathrm{p}=0.018$ ) compared to men. Players in the men's squad were $46 \%$ more likely to sustain an injury to the head $(\mathrm{RR}=0.54,95 \% \mathrm{CI}=0.32$ to $0.92, \mathrm{p}=0.010)$ compared to players in the women's squad. There were no other identifiable differences between the men and women in terms of body site injured and no identifiable differences in terms of the nature of the injuries sustained (Table 2). 
1 Table 1 Summary of injury distribution characteristics, players injured and incidence rate across the 2-seasons ( $\mathrm{n}=90$ rugby sevens players)

\begin{tabular}{|c|c|c|c|c|c|c|c|c|c|c|c|c|}
\hline & \multicolumn{3}{|c|}{ Season 2015/16 ${ }^{a}$} & \multicolumn{3}{|c|}{ Season 2016/17 ${ }^{a}$} & \multicolumn{3}{|c|}{ Total $^{b}$} & \multicolumn{3}{|c|}{ Seasons 2015/16 \& 2016/17 ${ }^{c}$} \\
\hline & Male & Female & Total & Male & Female & Total & Male & Female & Total & Male & Female & Total \\
\hline Total players, $n$ & 35 & 27 & 62 & 40 & 30 & 70 & 55 & 35 & 90 & 20 & 22 & 42 \\
\hline Injured players (\%) & $27(77.1)$ & $23(85.2)$ & $50(80.6)$ & $31(77.5)$ & $22(73.3)$ & $53(75.7)$ & $46(83.6)$ & $27(77.1)$ & $73(81.1)$ & $19(95.0)$ & $21(95.5)$ & $40(95.2)$ \\
\hline Non-injured players (\%) & $8(22.9)$ & $4(14.8)$ & $12(19.4)$ & $9(22.5)$ & $8(26.7)$ & $17(24.3)$ & $9(16.4)$ & $8(22.9)$ & $17(18.9)$ & $1(5.0)$ & $1(4.5)$ & $2(4.8)$ \\
\hline Total injuries sustained & 83 & 58 & 141 & 130 & 94 & 224 & 213 & 152 & 365 & 130 & 140 & 270 \\
\hline Time loss $(\%)$ & $73(88.0)$ & $49(84.5)$ & $122(86.5)$ & $96(73.8)$ & $71(75.5)$ & $167(74.6)$ & $169(79.3)$ & $120(78.9)$ & $289(79.2)$ & $109(83.8)$ & 109 (77.9) & $218(80.7)$ \\
\hline Non-time loss $(\%)$ & $10(12.0)$ & $9(15.5)$ & $19(13.5)$ & $34(26.2)$ & $23(24.5)$ & $57(25.4)$ & $44(20.7)$ & $32(21.1)$ & $76(20.8)$ & $21(16.2)$ & $31(22.1)$ & $52(19.3)$ \\
\hline $\begin{array}{l}\text { Median number of injury } \\
(I Q R)\end{array}$ & $2(2)$ & $2(2)$ & $2(2)$ & $3(4)$ & $3(5)$ & $3(4)$ & $3(6)$ & $4(6)$ & $3.5(6)$ & $7(5)$ & $6(4)$ & $7(4)$ \\
\hline Injury range & $0-8$ & $0-5$ & $0-8$ & $0-10$ & $0-10$ & $0-10$ & $0-12$ & $0-15$ & $0-15$ & $0-12$ & $0-15$ & $0-15$ \\
\hline Injury incidence rate $\mathrm{d}$ & 37.3 & 34.6 & 36.2 & 51.9 & 45.8 & 49.2 & 45.0 & 40.8 & 43.2 & 41.9 & 41.4 & 41.6 \\
\hline $95 \% \mathrm{CI}$ for incidence rate & $29.7-46.3$ & $26.3-44.7$ & $30.4-42.6$ & 43.4-61.6 & $37.0-56.1$ & $42.9-56.0$ & $39.2-51.5$ & $34.5-47.8$ & $38.8-47.8$ & $35.0-49.7$ & $34.8-48.9$ & $36.8-46.9$ \\
\hline \multicolumn{13}{|l|}{ Number of players (\%) with: } \\
\hline 0 injurie & $8(22.9)$ & $4(14.8)$ & $12(19.4)$ & $9(22.5)$ & $8(26.7)$ & $17(24.3)$ & $9(16.4)$ & $8(22.9)$ & $17(18.9)$ & $1(5.0)$ & $1(4.5)$ & $2(4.8)$ \\
\hline 1 injury & $4(11.4)$ & $6(22.2)$ & $10(16.1)$ & $5(12.5)$ & $4(13.3)$ & $9(12.9)$ & $8(14.5)$ & $3(8.6)$ & $11(12.2)$ & $0(0.0)$ & $0(0.0)$ & $0(0.0)$ \\
\hline 2 injuries & $7(20.0)$ & $7(25.9)$ & $14(22.6)$ & $5(12.5)$ & $1(3.3)$ & $6(8.6)$ & $8(14.5)$ & $2(5.7)$ & $10(11.1)$ & $2(10.0)$ & $1(4.5)$ & $3(7.1)$ \\
\hline 3-4 injuries & $11(31.4)$ & $7(25.9)$ & $18(29.0)$ & $8(20.0)$ & $9(30.0)$ & $17(24.3)$ & $8(14.5)$ & $8(22.9)$ & $16(17.8)$ & $3(15.0)$ & $6(27.3)$ & $9(21.4)$ \\
\hline 5-6 injuries & $4(11.4)$ & $3(11.1)$ & $7(11.3)$ & $6(15.0)$ & $4(13.3)$ & $10(14.3)$ & $8(14.5)$ & $4(11.4)$ & $12(13.3)$ & $2(10.0)$ & $4(18.2)$ & $6(14.3)$ \\
\hline 7-8 injuries & $1(2.9)$ & $0(0.0)$ & $1(1.6)$ & $5(12.5)$ & $2(6.7)$ & $7(10.0)$ & $8(14.5)$ & $7(20.0)$ & 15 (16.7) & $6(30.0)$ & $7(31.8)$ & $13(31.0)$ \\
\hline 9-10 injuries & $0(0.0)$ & $0(0.0)$ & $0(0.0)$ & $2(5.0)$ & $2(6.7)$ & $4(5.7)$ & $4(7.3)$ & $0(0.0)$ & $4(4.4)$ & $4(20.0)$ & $0(0.0)$ & $4(9.5)$ \\
\hline 11-15 injuries & $0(0.0)$ & $0(0.0)$ & $0(0.0)$ & $0(0.0)$ & $0(0.0)$ & $0(0.0)$ & $2(3.6)$ & $3(8.6)$ & $5(5.6)$ & $2(10.0)$ & $3(13.6)$ & $5(11.9)$ \\
\hline
\end{tabular}


${ }^{a}$ Injuries are only reported under 2015/16 or 2016/17 if they were sustained during that season; that is if a player sustains 6 injuries in the $2015 / 16$ season they are

2 considered under the "Number of players with 5-6 injuries" row

$3{ }^{b}$ The accumulated total of injuries throughout the 2-seasons of surveillance; inclusive of all 90 players who were under surveillance for at least 1-season; if an athlete who

4 was involved for both seasons sustained 12 injuries throughout this period they are considered under the "Number of players with 11-15 injuries" row

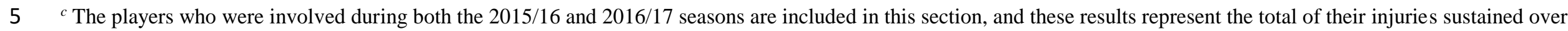

6 the two seasons combined

$7 \quad$ d Injuries per 1000 player hours

$8 \mathrm{n}=$ number of players 
Table 2 Distribution and days of time-loss for all injuries sustained across the 2015/16-2016/17 seasons by body region, body site, injury nature (total of 73 injured players (46 men and 27 women) over the 2-year surveillance period)

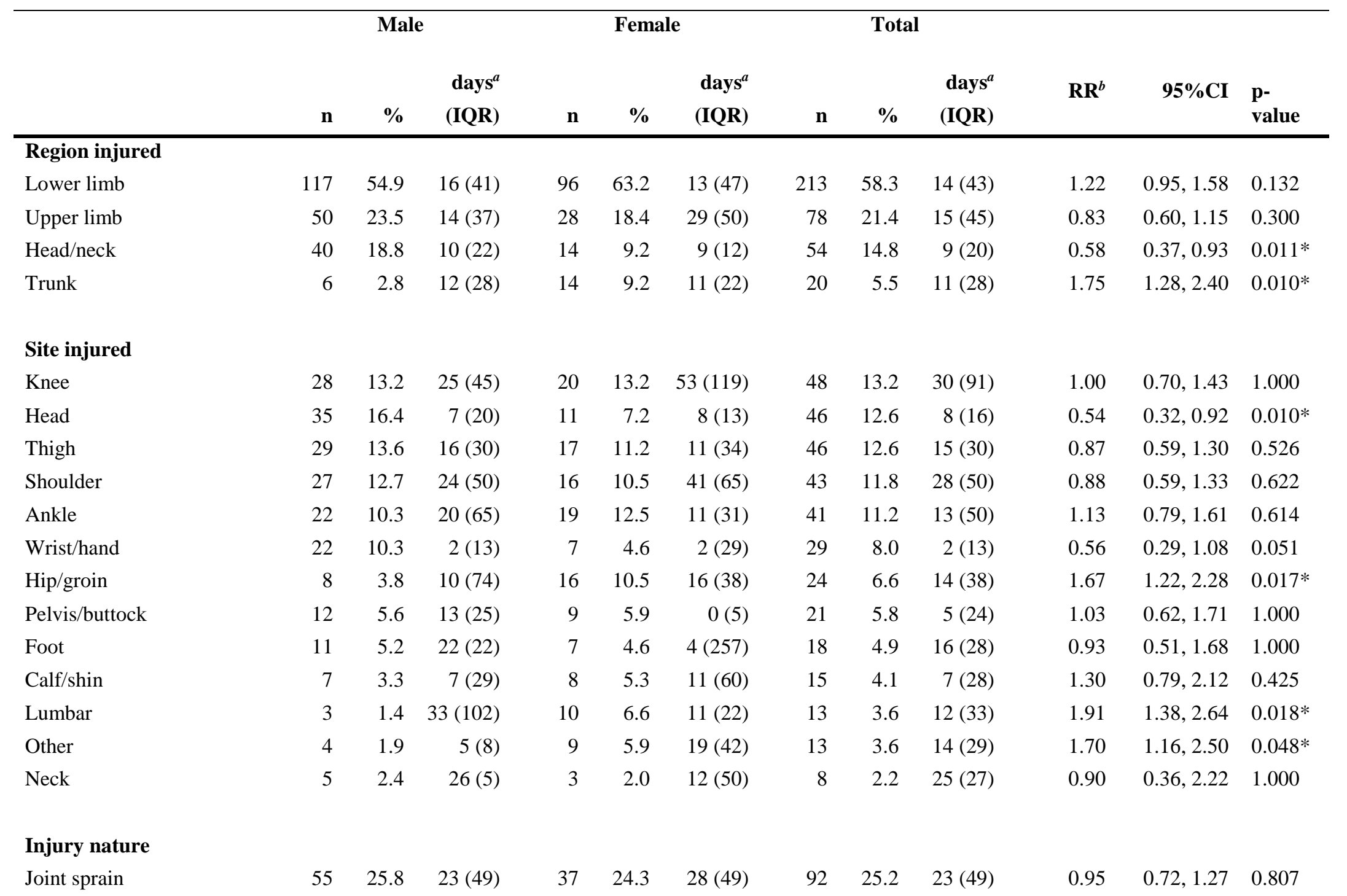




$\begin{array}{lrrrrrrrrrrrr}\text { Muscle injury } & 30 & 14.1 & 15(30) & 31 & 20.4 & 9(16) & 61 & 16.7 & 11(22) & 1.28 & 0.96,1.69 & 0.119 \\ \text { Haematoma/laceration } & 33 & 15.5 & 8(7) & 16 & 10.5 & 17(20) & 49 & 13.4 & 9(11) & 0.75 & 0.50,1.16 & 0.213 \\ \text { Tendon injury } & 25 & 11.7 & 20(26) & 19 & 12.5 & 4(58) & 44 & 12.1 & 10(57) & 1.04 & 0.72,1.50 & 0.871 \\ \text { Cartilage injury/impingement } & 21 & 9.9 & 23(33) & 13 & 8.6 & 12(46) & 34 & 9.3 & 19(30) & 0.91 & 0.58,1.42 & 0.718 \\ \text { Neural/CNS injury } & 17 & 8.0 & 12(15) & 6 & 4.0 & 8(10) & 23 & 6.3 & 11(9) & 0.61 & 0.30,1.23 & 0.132 \\ \text { Other } & 9 & 4.2 & 28(38) & 13 & 8.6 & 44(93) & 22 & 6.0 & 28(84) & 1.46 & 1.01,2.11 & 0.117 \\ \text { Joint dislocation/instability } & 12 & 5.6 & 16(78) & 8 & 5.3 & 64(125) & 20 & 5.5 & 32(119) & 0.96 & 0.55,1.66 & 1.000 \\ \text { Bone injury } & 11 & 5.2 & 25(35) & 9 & 5.9 & 19(46) & 20 & 5.5 & 23(42) & 1.09 & 0.66,1.79 & 0.817 \\ & & & & & & & & & & \end{array}$

${ }^{a}$ The median number of days of time-loss

$2{ }^{b} \mathrm{RR}=$ relative risk calculated using Fisher's exact test comparing the injuries between men and women with men as the reference category

$3 \mathrm{IQR}=$ interquartile range; $\mathrm{n}=$ number of injuries; $\mathrm{CI}=$ confidence interval; * indicates a statistically significant difference 

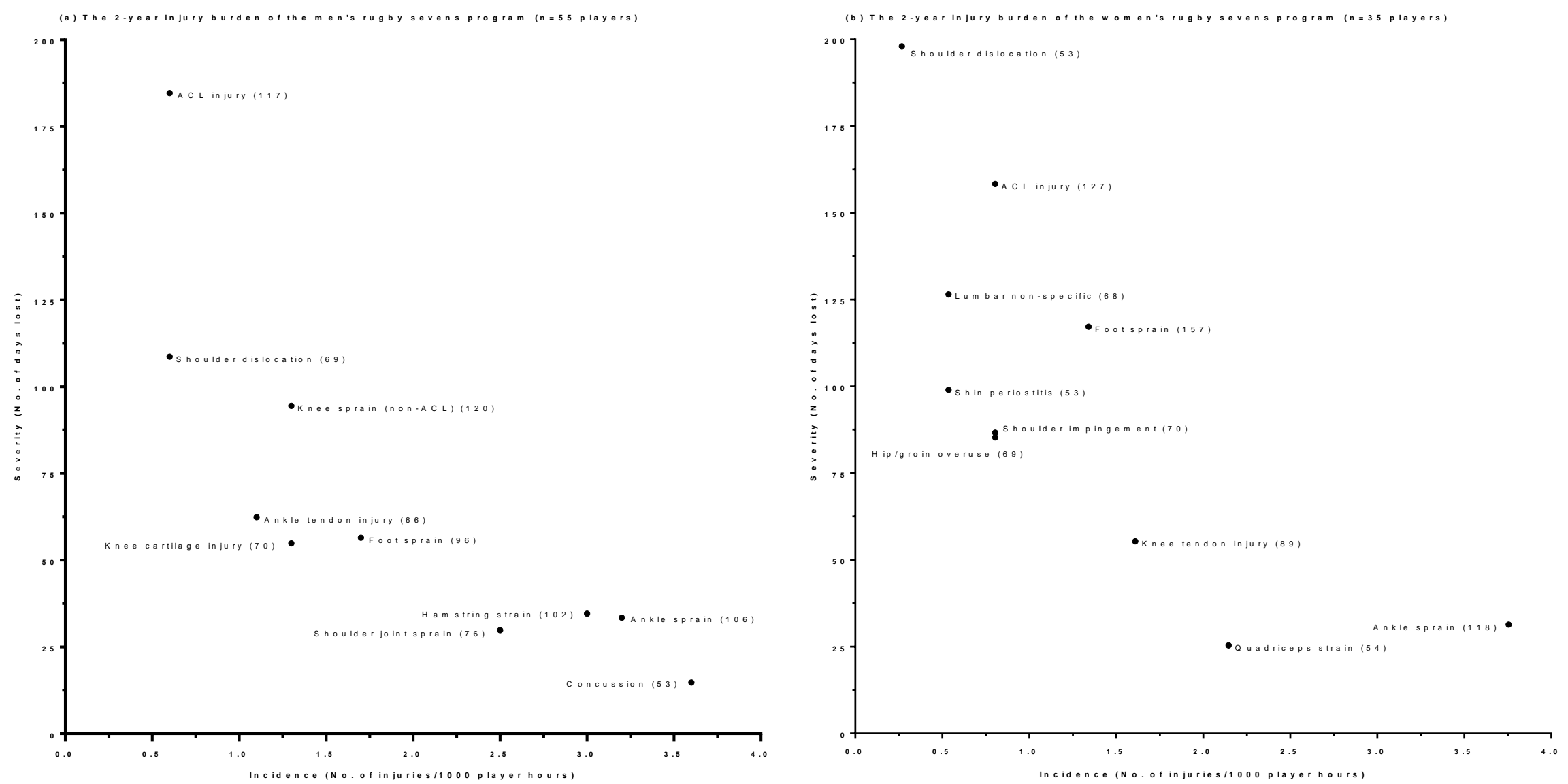

2 Fig 1 Relationship between the injury burden (number of injuries/1000 player hours $x$ total days lost to injury (i.e. severity)) for the ten injury types with the largest burden 3 for the men's and women's rugby sevens squads 
The injuries with the highest burden for the men's squad were non-ACL knee injuries (120 days absence/1000 player-hours), ACL knee injuries (117 days absence/1000 player-hours, and ankle sprains (106 days absence/1000 player-hours). In the women's squad, the highest burdens were attributable to foot sprains (157 days absence/1000 player-hours), ACL injuries (124 days absence/1000 player-hours) and ankle sprains (118 days absence/1000 player-hours). Other notable differences in injury burden between the two squads included the men having a higher burden compared to the women for hamstring strains (103 compared with 31 days absence/1000 player-hours) and concussion (53 compared with 9 days absence/1000 player-hours) (Fig 1).

\section{Subsequent injuries}

Over the 2-year period, $38(69.1 \%)$ men and 24 (68.6\%) women sustained at least two injuries. Overall, the median number of injuries increased from 2 (range=0-8) in the 2015-16 season to 3 (range=0-10) in the 2016-17 season. Of the 42 players who participated in both seasons, 40 (95.2\%) sustained at least one subsequent injury, with $5(11.9 \%)$ sustaining between 11 and 15 injuries over the 2-year period.

The majority $(80.7 \%)$ of subsequent injuries sustained were to a different site and of a different nature (SIC-2.0 category VIII), with $10.3 \%$ of all subsequent injuries to a different site but of the same nature (SIC-2.0 category VII (injury) and $6.1 \%$ to the same site but of a different nature (SIC-2.0 category VI (injury) (Fig 2.) The SIC2.0 category allocation for each injury number sustained demonstrates that for each successive injury sustained, the general category allocation of subsequent injury types remains quite constant. The SIC-2.0 category VIII was clearly the most common category type over each injury number (75.6\% to $92.3 \%)$, with small deviations noted for categories VI and VIIs over successive injury occurrences. The subsequent injury SIC-2.0 categories II (re-injury after recovery, to the same site, same nature, same side, and same structure), III (exacerbation before recovery, to the same site, same nature, same side, and same structure), IV (injury to the same site, same nature, same side, but of a different structure) and V (injury to the same site, same nature, but different side of the body) accounted for less than $2.9 \%$ of all subsequent injury relationship to previous injuries.

Following an initial injury, the severity of time loss days for each successive injury declined. Injuries sustained following the fourth injury were typically of a reduced severity than the injuries that preceded them (Fig 3). A general decline in the volume of workload completed preceding each successive injury was observed with each successive injury sustained (Fig 4). The number of days remaining injury free before injury occurrence reduces gradually as each successive injury was sustained, indicating that the days of survival, remaining injury free, in rugby sevens participation is reduced with each successive injury. A similar trend was also observed for the 


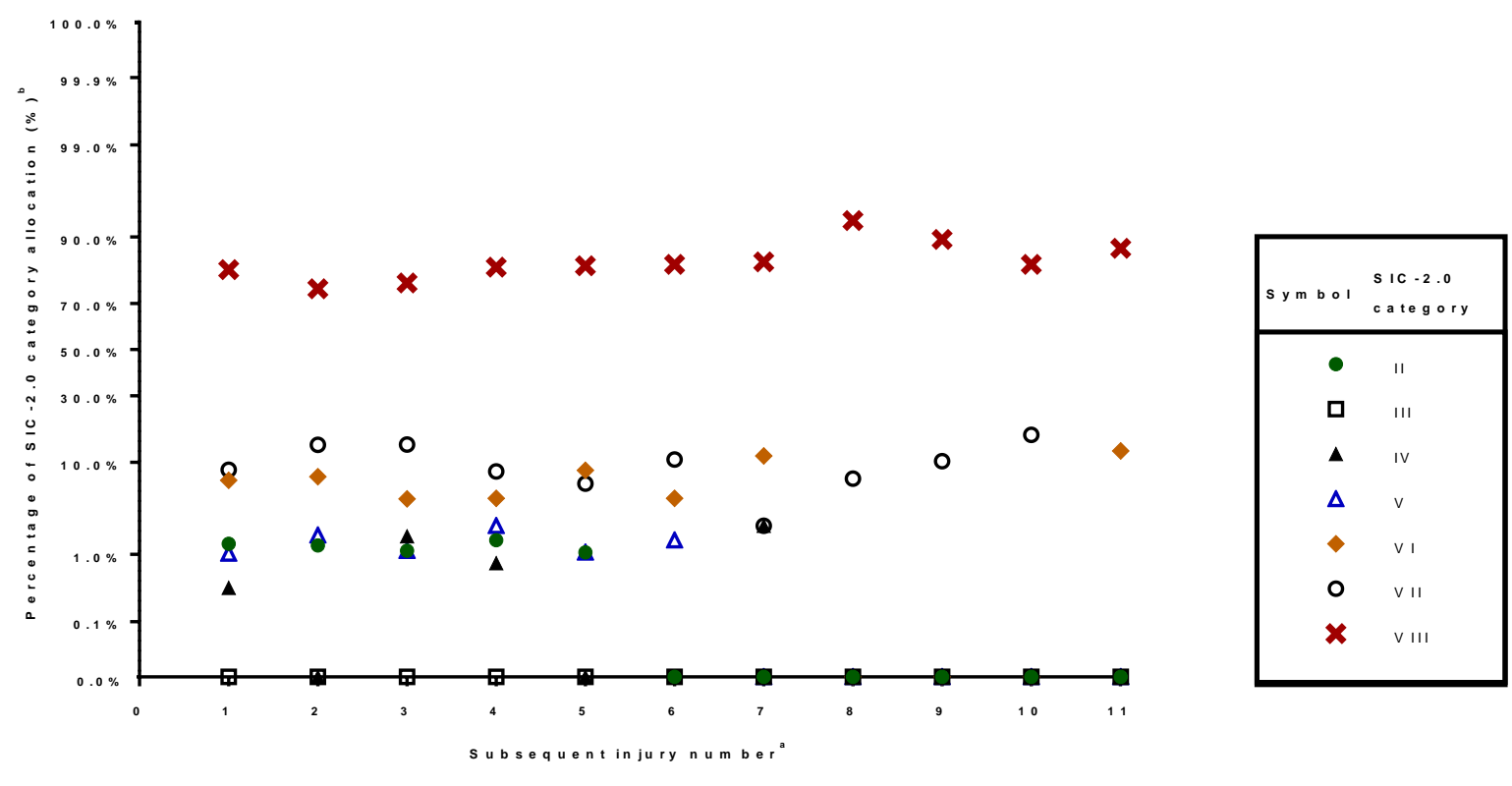

5

number of on-field minutes participated in before the occurrence of each injury. Accumulated workloads measured in total distance covered and running high speed metres before injury occurrence, were also observed to generally decline as a larger number of successive injuries are sustained.
$6 \quad$ Fig 2 The distribution of subsequent injury categories (SIC-2.0) for each individual injury number sustained

$7 \quad{ }^{a}$ Successive subsequent injury counts greater than 11 were not included as only one player sustained more than $8 \quad 12$ injuries

$9 \quad \mathrm{~b}$ Probability percentage scale, SIC-2.0 category allocation percentage

Legend for the key titled SIC-2.0 category:

SIC-2.0 II - Re-injury after recovery, to the same site, same nature, same side, and same structure and same structure SIC-2.0 IV - Injury to the same site, same nature, same side, but of a different structure 


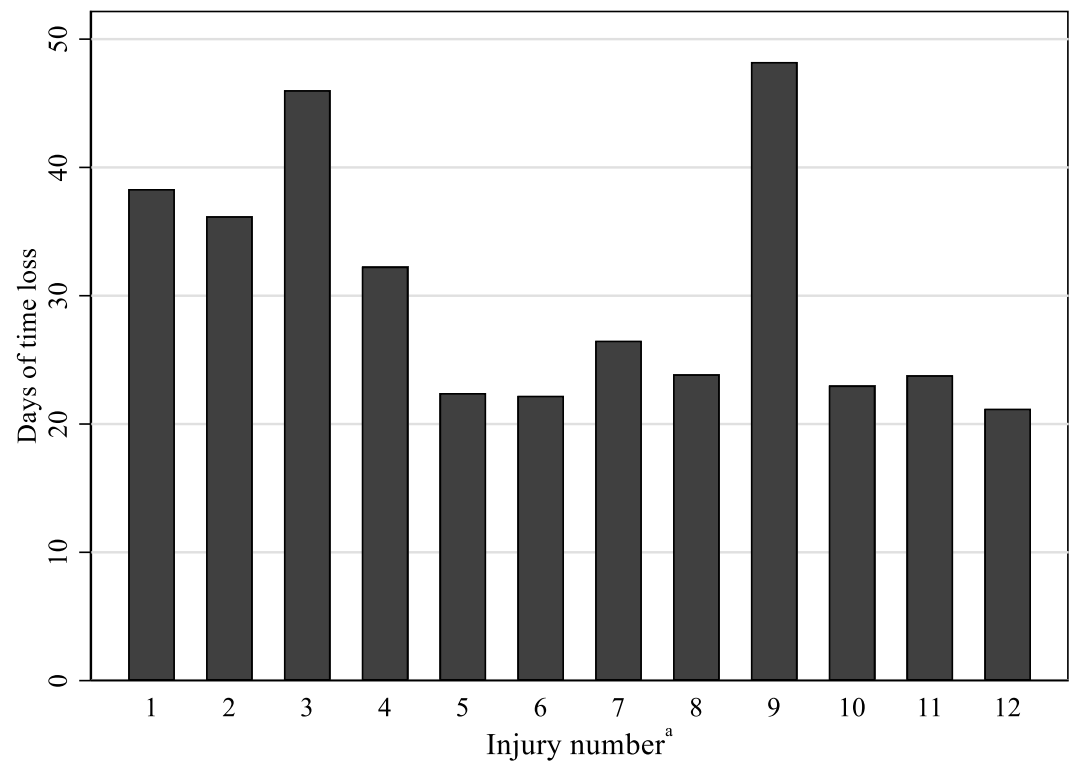

1

2 Fig 3 Time loss days (mean) for each successive injury sustained (n=362 injuries in 72 rugby sevens players)

3 a Successive injury counts greater than 12 were not included as only one player sustained more than 12 injuries 

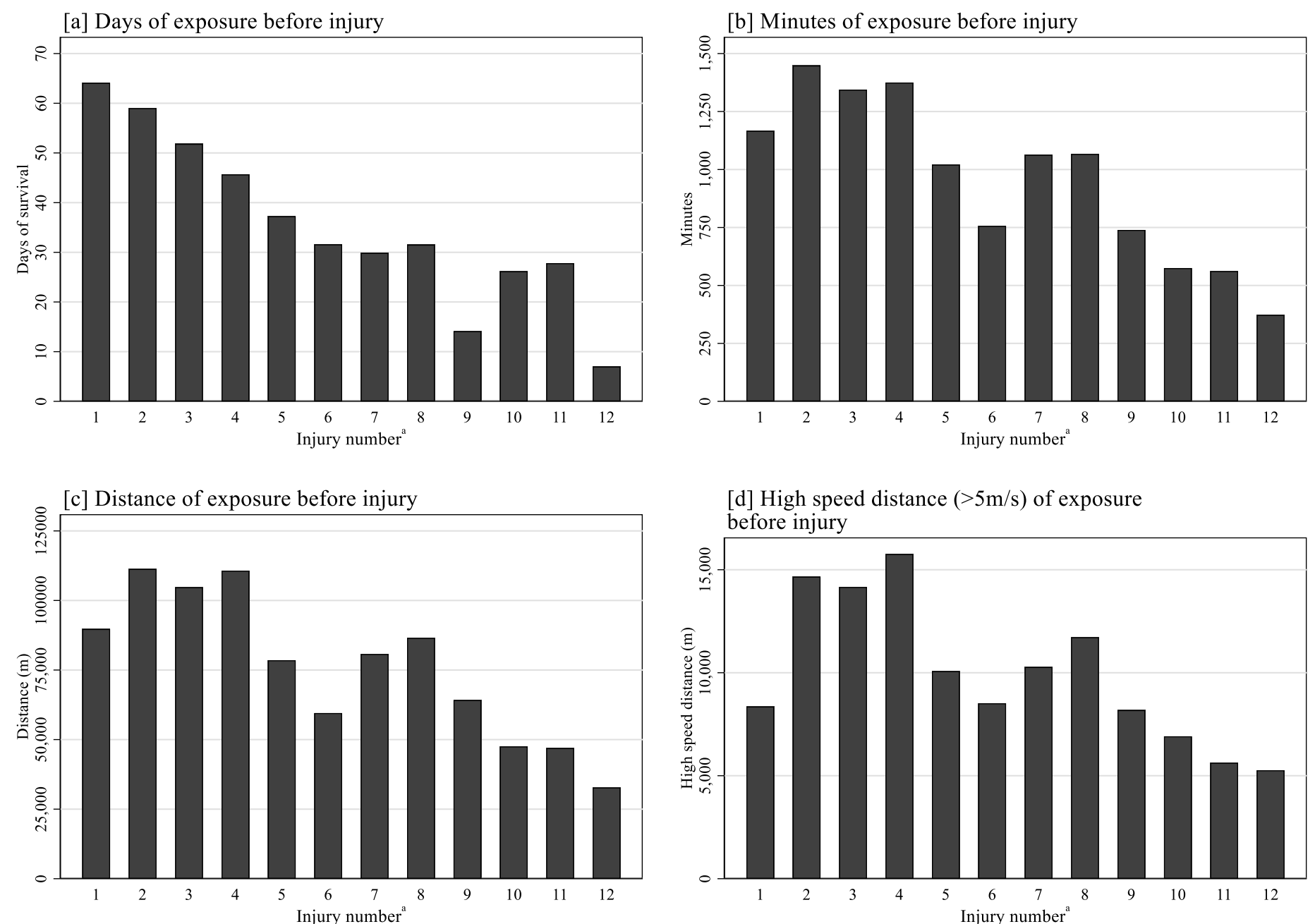

1

2 Fig 4 The mean exposure before the occurrence of each succussive injury sustained (n=362 injuries in 72 rugby sevens players)

$3 \quad$ a Successive injury counts greater than 12 were not included as only one player sustained more than 12 injuries 


\section{DISCUSSION}

This study is the first to describe injury and subsequent injury occurrence for rugby sevens over an extended continuous surveillance period inclusive of both match and training related injuries for both men and women.

The men were found to have an increased risk of sustaining an injury compared to the women, with differences in injury profiles observed between men and women. More than two-thirds of the players sustained at least one subsequent injury, with the majority of subsequent injuries occurring at a different site and of a different nature to previous injuries. Workload and time exposure before injury was observed to substantially reduce after the occurrence of each successive injury, suggesting that a player commonly becomes less tolerant to the required workloads and increasing susceptible to subsequent injury following an accumulation of previous injuries.

These findings provide a basis for future exploration into the aetiology and mechanisms of subsequent injury, particularly investigating tertiary prevention strategies for mitigating the risk of subsequent injury occurrence in rugby sevens.

\section{Injury occurrence}

The 2-year injury incidence rate of 40.8 and 45.0 per 1000 player hours respective for the women's and men's programs, were lower than previously reported in men's rugby sevens, where incidence rates have been as high as 119.8 per 1000 hours. ${ }^{3}$ Previous research has been limited to recording player exposure and injuries during tournaments only, ${ }^{3,22,29}$ whereas this study also considered training sessions completed outside of tournaments. Training represents a significant proportion of the workload completed over the season, therein serving to dilute the injuries with greater exposure hours, which could explain why the IIRs reported in this study are lower than those previously published in men's rugby sevens. ${ }^{24}$ There have been few data reported in elite female rugby sevens players to date, but the findings here are similar to those reported in a cohort of elite American players where an IIR of 46.4 per 1000 player hours was found over a 4-year surveillance period using a time-loss match only injury definition. ${ }^{29}$ The increase in the rate of injuries for both the men's and women's squads over the 2015-16 and 2016-17 seasons was a finding of interest. It is possible that this increase could be explained through improved injury reporting practices by the squad's medical staff in the second season of the study, however this hypothesis warrants further investigation.

\section{Different injury profiles in men's and women's rugby sevens}

In many contact sports, differences in injury profiles are apparent in men and women, with key examples of higher ACL in the knee, concussion and wrist/hand fractures in women. ${ }^{9}$ Challenges in comparing injury types 
between sexes exist as often data is collected in different ways across studies. In this study, the data collection, injury definitions and local training facilities were homogeneous for men and women supporting the direct comparison of injury types. The differences observed, between sexes, may be accounted for by specific styles of play or training modalities, though further investigation to clarify the injury disparity between sexes is needed. Identification that injuries profiles are different for men and women, informs future injury prevention research that prevention strategies made need to be tailored according to gender.

\section{Subsequent injury characteristics in rugby sevens}

Subsequent injury occurrence accounted for the majority of injuries sustained, which has been previously established in other contact and team ball sports. ${ }^{10,36}$ The finding that the majority of subsequent injuries were to a different site and different nature (SIC-2.0 category VIII), is comparable to the findings previously identified in Australian rugby sevens players where $78.7 \%$ of all subsequent injuries were found to be SIC-2.0 category VIII subsequent injuries. ${ }^{37}$ The small variation in the distribution of SIC-2.0 category allocation when analysed over a number of successive injuries suggests that the relationship between injury and previous injury does not substantially change over time as more injuries are sustained.

Contrary to previous research in rugby union, the severity of injury was not found to increase with a greater number of injuries being sustained. ${ }^{41}$ In fact, an overall trend in injury severity reduction was observed following the fourth occurrence of injury. Recent research in subsequent injury occurrence in rugby union, has also demonstrated that subsequent injury occurrence was not associated with an increased severity of injury compared to previous injuries. ${ }^{40}$ Future research should focus on the effect of accumulated days lost through multiple injury occurrences rather than the severity of each injury being the prime focus in injury analysis.

The reduction in time and workload exposure preceding injury occurrence observed with successive injury occurrence, suggests that player robustness to injury was reduced as a greater number of injuries were sustained. This indicates that a player is completing smaller on-field workload volumes before the onset of successive subsequent injuries, meaning that they survival for shorter volumes of training before they sustain the next subsequent injury. Time to injury has been demonstrated to be progressively shorter following the occurrence of an increasing number of injuries in Australian football within a singular season. ${ }^{6}$ It has been proposed that substantial workload completion following an injury should be a key consideration in the return to play (RTP) decision process to reduce the risk for future injury occurrence. ${ }^{2}$ In elite Australian football, an accelerated rehabilitation process following injury to expedite the RTP process was associated with a higher risk of 
subsequent injury. ${ }^{35}$ Protective effects against future subsequent injury were seen when RTP was delayed, possibly due to the greater accumulated running and high speed running workloads. ${ }^{35}$ The reduced durations and distances completed by the players in this present study with increases in subsequent injury occurrence, suggests a possible causal link between workload and risk of subsequent injury.

Our injury results have new implications for clinical practice in the areas of injury rehabilitation and return to play. While subsequent injuries may not be of increased severity, the time a player remains injury free following injury appears to reduce, resulting in an increased accumulated injury burden overall. Investigation into associated injury aetiology and mechanisms of subsequent injury occurrence to guide the development of tertiary injury prevention strategies is warranted to mitigate the risk of subsequent injury occurrence in rugby sevens.

\section{Strengths and limitations}

This study provides a comprehensive overview of match and training injury in rugby sevens, including male and female elite players over two seasons. The use of individual player GPS data allowed for accurate exposure measures to be used, removing the assumptions that are commonly made in exposure calculations when estimates of player minutes are derived from team averages, which is a limitation of previous research in rugby sevens. ${ }^{3}$

Similar to previous research in rugby sevens, exposure measures only accounted for time on-field, excluding the effect of other training modalities such as gym and weights sessions. These training sessions are likely to influence injury risk, so future capture and quantification of these sessions should be considered. A number of the players within the squads did not complete both seasons, nor did all players complete the entirety of a season. Therefore, the injury results may be biased by those players who were under surveillance for a longer duration and who would also have been more likely to sustain an injury because of longer periods of exposure. Relationships to any injuries that were sustained prior to the surveillance period could not be analysed. This remains a limitation to all subsequent injury research and application of existing subsequent injury frameworks. ${ }^{5,} 37$ There was incomplete capture of injury mechanism and activity data and these variables were not included in the analysis, which was a limitation of this study.

\section{Recommendations for future research}




\section{CONCLUSION}

8

\section{REFERENCES}

As demonstrated in this study, it is important that injury studies in rugby sevens moves towards longitudinal analysis, extending beyond single tournaments or match-only injuries. ${ }^{7,} 10$ The links identified between subsequent injuries in rugby sevens should be explored as there are important implications on future injury risks following an accumulation of previous injuries. This will help to inform the development of future targeted injury prevention programs in rugby sevens.

A trend for a higher IIR in male players was observed compared to the female players, with distinct differences in injury profiles identified between both groups. The most commonly injured sites were the head, thigh and knee for men and the knee, ankle and thigh for women. The injury types with the largest burden were non-ACL knee and ACL injuries for men, and foot sprains and ACL injuries for women. Rugby sevens players commonly sustained multiple subsequent injuries which were typically different to their previous injuries. With successive subsequent injury occurrence, player susceptibility to future injury appears to increase. Thus, following injury the risk profile for future injury occurrence is altered. This research serves as an important start point for further investigation of injury aetiology and mechanisms in rugby sevens to inform injury prevention strategies.

1. Archbold HAP, Rankin AT, Webb M, et al. Recurrent injury patterns in adolescent rugby. Physical Therapy in Sport. 2018;33:12-17.

2. Blanch $\mathrm{P}$, Gabbett TJ. Has the athlete trained enough to return to play safely? The acute:chronic workload ratio permits clinicians to quantify a player's risk of subsequent injury. British Journal of Sports Medicine. 2016;50(8):471-475.

3. Cruz-Ferreira A, Cruz-Ferreira E, Santiago L, Taborda Barata L. Epidemiology of injuries in senior male rugby union sevens: a systematic review. The Physician and Sportsmedicine. 2016:1-8.

4. Cruz-Ferreira AM, Cruz-Ferreira EM, Silva JD, Ferreira RM, Santiago LM, Taborda-Barata L. Epidemiology of injuries in Portuguese senior male rugby union sevens: a cohort prospective study. The Physician and Sportsmedicine. 2018;46(2):255-261. 
1 5. Finch CF, Cook J. Categorising sports injuries in epidemiological studies: the subsequent injury categorisation (SIC) model to address multiple, recurrent and exacerbation of injuries. British Journal of Sports Medicine. 2014;48:1276-1280.

6. Finch CF, Cook J, Kunstler BE, Akram M, Orchard J. Subsequent injuries are more common than injury recurrences: an analysis of 1 season of prospectively collected injuries in professional Australian football. The American Journal of Sports Medicine. 2017;45(8):1921-1927.

7. Finch CF, Fortington LV. So you want to understand subsequent injuries better? Start by understanding the minimum data collection and reporting requirements. Online First: 30 November 2017 as 10.1136/bjsports-2017-098225.

8. Finch CF, Marshall SW. Let us stop throwing out the baby with the bathwater: towards better analysis of longitudinal injury data. British Journal of Sports Medicine. 2016;50(12):712-715.

9. Fortington LV, Finch CF. Priorities for injury prevention in women's Australian football: a compilation of national data from different sources. BMJ Open Sport \& Exercise Medicine. 2016;2(1):doi: 10.1136/bmjsem-2015-000101.

10. Fortington LV, van der Worp H, van den Akker-Scheek I, Finch CF. Reporting multiple individual injuries in studies of team ball sports: a systematic review of current practice. Sports Medicine. 2017;47(6):1103-1122.

11. Fuller C, Taylor A. Sevens world series \& RWC sevens - injury epidemiology results: 2008 to 2013. International Rugby Board. Available at: http://www.irbplayerwelfare.com/?documentid=108.

12. Fuller C, Taylor A. Women's sevens challenge cup, women's sevens world series, rugby world cup sevens - injury epidemiology results: 2011 to 2013. International Rugby Board. Available at: http://www.irbplayerwelfare.com/?documentid=120.

13. Fuller C, Taylor A. Sevens world series (men) - injury epidemiology results: 2008/09 to 2013/14. International Rugby Board. Available at: http://www.irbplayerwelfare.com/?documentid=136. 
1 14. Fuller C, Taylor A. Women's sevens world series - injury surveillance summary of results: 2011/12 to 2013/14. International Rugby Board.

15. Fuller C, Taylor A. Sevens world series (men) summary results: 2008/09 to 2014/15. International Rugby Board. Available at: http://www.irbplayerwelfare.com/?documentid=159.

16. Fuller C, Taylor A. Women's sevens world series - injury surveillance summary of results: 2011/12 to 2014/15. International Rugby Board. Available at: http://www.irbplayerwelfare.com/?documentid=160.

17. Fuller CW. Injury risk (burden), risk matrices and risk contours in team sports: a review of principles, practices and problems. Sports Medicine. 2018;48(7):1597-1606.

18. Fuller CW. Modelling injury-burden in rugby sevens. Journal of Science and Medicine in Sport. 2018;21(6):553-557.

19. Fuller CW, Molloy MG, Bagate $\mathrm{C}$, et al. Consensus statement on injury definitions and data collection procedures for studies of injuries in rugby union. British Journal of Sports Medicine. 2007;41(5):328331.

20. Fuller CW, Taylor A, Molloy MG. Epidemiological study of injuries in international rugby sevens. Clinical Journal of Sport Medicine. 2010;20(3):179-184.

21. Fuller CW, Taylor A, Raftery M. Epidemiology of concussion in men's elite rugby-7s (sevens world series) and rugby-15s (rugby world cup, junior world championship and rugby trophy, pacific nations cup and English premiership). British Journal of Sports Medicine. 2015;49(7):478-483.

22. Fuller CW, Taylor A, Raftery M. 2016 Rio Olympics: an epidemiological study of the men's and women's rugby-7s tournaments. British Journal of Sports Medicine. 2017;51(17):1272-1278.

23. Fuller CW, Taylor AE, Raftery M. Should player fatigue be the focus of injury prevention strategies for international rugby sevens tournaments? British Journal of Sports Medicine. 2016;50(11):682-687. 
24. Higham DG, Pyne DB, Anson JM, Hopkins WG, Eddy A. Comparison of activity profiles and physiological demands between international rugby sevens matches and training. The Journal of Strength \& Conditioning Research. 2016;30(5):1287-1294.

25. Lopez Jr V, Ma R, Weinstein MG, et al. Concussive injuries in rugby-7s: an American experience and current review. Medicine and Science in Sports and Exercise. 2016;48(7):1320-1330.

26. Lopez V, Galano GJ, Black CM, et al. Profile of an American Amateur Rugby Union Sevens Series. The American Journal of Sports Medicine. 2011;40(1):179-184.

27. Lopez V, Galano GJ, Black CM, et al. Profile of an American amateur rugby union sevens series. The American Journal of Sports Medicine. 2012;40(1):179-184.

28. Ludbrook J. Analysis of $2 \times 2$ tables of frequencies: matching test to experimental design. International Journal of Epidemiology. 2008;37(6):1430-1435.

29. Ma R, Lopez V, Jr., Weinstein MG, et al. Injury profile of American women's rugby-7s. Med Sci Sports Exerc. 2016;48(10):1957-1966.

30. Mitchell JA, Pumpa KL, Pyne DB. Responses of lower-body power and match running demands following long-haul travel in international rugby sevens players. J Strength Cond Res. 2017;31(3):686695.

31. Moore IS, Mount S, Mathema P, Ranson C. Application of the subsequent injury categorisation model for longitudinal injury surveillance in elite rugby and cricket: intersport comparisons and inter-rater reliability of coding. British Journal of Sports Medicine. 2017;doi: 10.1136/bjsports-2016-097040.

32. Rae K, Orchard J. The Orchard sports injury classification system (OSICS) version 10. Clin J Sport Med. 2007;17(3):201-204.

33. Ross A, Gill N, Cronin J. Match analysis and player characteristics in rugby sevens. Sports Medicine. 2014;44(3):357-367. 
1 34. Ross A, Gill N, Cronin J. The match demands of international rugby sevens. Journal of Sports Sciences. 2015;33(10):1035-1041.

35. Stares J, Dawson B, Peeling P, et al. How much is enough in rehabilitation? High running workloads following lower limb muscle injury delay return to play but protect against subsequent injury. Journal of Science and Medicine in Sport. 2018.

36. Toohey LA, Drew MK, Cook JL, Finch CF, Gaida JE. Is subsequent lower limb injury associated with previous injury? A systematic review and meta-analysis. British Journal of Sports Medicine. 2017;51(23):1670-1678.

37. Toohey LA, Drew MK, Fortington LV, Finch CF, Cook JL. An updated subsequent injury categorisation model (SIC-2.0): data-driven categorisation of subsequent injuries in sport. Sports Medicine. 2018;48(9):2199-2210.

38. Tucker R. Rugby sevens: Olympic debutante and research catalyst. British Journal of Sports Medicine. 2016;50(11):638-639.

39. von Elm E, Altman DG, Egger M, et al. The Strengthening the Reporting of Observational Studies in Epidemiology (STROBE) Statement: Guidelines for Reporting Observational Studies. PLOS Medicine. 2007;4(10):e296.

40. Williams $\mathrm{S}$, Trewartha $\mathrm{G}$, Kemp S, et al. Subsequent injuries and early recurrent diagnoses in elite rugby union players. Int J Sports Med. 2017;38(10):791-798.

41. Williams S, Trewartha G, Kemp S, Stokes K. A meta-analysis of injuries in senior men's professional rugby union. Sports Medicine. 2013;43(10):1043-1055. 